\title{
Probing $\mathbf{C}-\mathbf{O}$ bond activation on gas-phase transition metal clusters: Infrared multiple photon dissociation spectroscopy of $\mathrm{Fe}, \mathrm{Ru}, \mathrm{Re}$, and $\mathbf{W}$ cluster $\mathrm{CO}$ complexes
}

\author{
Jonathan T. Lyon, ${ }^{1, a)}$ Philipp Gruene, ${ }^{1}$ André Fielicke, ${ }^{1, b)}$ Gerard Meijer, ${ }^{1}$ and \\ David M. Rayner ${ }^{2}$ \\ ${ }^{1}$ Fritz-Haber-Institut der Max-Planck-Gesellschaft, Faradayweg 4-6, Berlin D-14195, Germany \\ ${ }^{2}$ Steacie Institute for Molecular Sciences, National Research Council, 100 Sussex Drive, \\ Ottawa, Ontario K1A OR6, Canada
}

(Received 27 July 2009; accepted 10 October 2009; published online 10 November 2009)

\begin{abstract}
The binding of carbon monoxide to iron, ruthenium, rhenium, and tungsten clusters is studied by means of infrared multiple photon dissociation spectroscopy. The CO stretching mode is used to probe the interaction of the $\mathrm{CO}$ molecule with the metal clusters and thereby the activation of the $\mathrm{C}-\mathrm{O}$ bond. $\mathrm{CO}$ is found to adsorb molecularly to atop positions on iron clusters. On ruthenium and rhenium clusters it also binds molecularly. In the case of ruthenium, binding is predominantly to atop sites, however higher coordinated $\mathrm{CO}$ binding is also observed for both metals and becomes prevalent for rhenium clusters containing more than nine atoms. Tungsten clusters exhibit a clear size dependence for molecular versus dissociative $\mathrm{CO}$ binding. This behavior denotes the crossover to the purely dissociative $\mathrm{CO}$ binding on the earlier transition metals such as tantalum.

(C) 2009 American Institute of Physics. [doi:10.1063/1.3257687]
\end{abstract}

\section{INTRODUCTION}

The binding of carbon monoxide to transition metals has been widely studied due, in part, to its technological importance, e.g., the Fischer-Tropsch synthesis for the production of synthetic fuels. ${ }^{1}$ For a metal to be an appropriate catalyst, it must bind to carbon monoxide sufficiently strongly to weaken the $\mathrm{CO}$ triple bond. However, the interaction of the metal with either carbon or oxygen must be sufficiently weak in order to allow for subsequent reactions. This is generally fulfilled by the elements in the middle of the transition metal series and leads, for instance, to the high activity of ruthenium and cobalt for $\mathrm{CO}$ methanation. ${ }^{2}$ These metals mark the transition from dissociative to molecular binding of $\mathrm{CO}$ for the $3 d$ and $4 d$ metals, respectively. According to Brodèn et $a l .{ }^{3,4}$ dissociative $\mathrm{CO}$ binding is found at room temperature for the metals left of a diagonal through the periodic system formed by the elements cobalt, ruthenium, and rhenium. For all metals we previously studied, it is seen that the transition from dissociative to molecular binding of carbon monoxide to surfaces also holds for $\mathrm{CO}$ bound to gas-phase metal clusters. Carbon monoxide binds dissociatively to clusters of the early transition metals $\mathrm{V}$ (Ref. 5) and $\mathrm{Nb},{ }^{6}$ but molecularly to clusters of $\mathrm{Co},{ }^{7} \mathrm{Rh},{ }^{7-9} \mathrm{Ni},{ }^{7,10} \mathrm{Pd},{ }^{10} \mathrm{Pt},{ }^{10}$ and $\mathrm{Au} .{ }^{11,12}$

The interplay of bond formation between $\mathrm{CO}$ and the metal and the activation of the $\mathrm{C}-\mathrm{O}$ bond is classically described within the Blyholder model. ${ }^{13}$ The $\mathrm{CO} 5 \sigma$ orbital interacts with initially unoccupied $d$ orbitals of the metal

\footnotetext{
${ }^{a)}$ Present address: Department of Natural Sciences, Clayton State University, 2000 Clayton State Blvd., Morrow, GA 30260, USA.

b) Author to whom correspondence should be addressed. Electronic mail: fielicke@fhi-berlin.mpg.de.
}

center ( $\sigma$ donation), while filled metal $d$ orbitals interact with the CO $\pi^{*}$ orbital ( $\pi$ back bonding). The strength of the back bonding, and the related weakening of the $\mathrm{C}-\mathrm{O}$ bond, depends on the number of metal atoms the $\mathrm{CO}$ is bound with and the electron density at the metal center. As the $\mathrm{C}-\mathrm{O}$ bond strength is sensitive to the binding site on metals, the COmetal system is often studied as a useful model to characterize binding sites at metal centers. The relative strength of the $\mathrm{C}-\mathrm{O}$ bond can be conveniently probed via vibrational spectroscopy; for gas-phase cluster complexes this information can be obtained by means of infrared multiple photon dissociation (IR-MPD) spectroscopy.

Using this technique it has been found that $\mathrm{CO}$ binds to clusters of the late $3 d$ metals only at atop sites, but for rhodium and palladium clusters also to more coordinated sites. For the $5 d$ metals $\mathrm{Pt}$ and $\mathrm{Au}$, again only binding to atop sites is observed. ${ }^{14}$ Going from CO binding to atop sites, via bridge sites, to hollow sites on the metal clusters typically redshifts the observed $\mathrm{C}-\mathrm{O}$ stretching frequency, $\nu(\mathrm{CO})$, approximately by $150 \mathrm{~cm}^{-1}$. For any given cluster size, $\nu(\mathrm{CO})$ redshifts going from cationic to neutral to anionic clusters due to the increase in electron density on the metal and stronger back bonding. ${ }^{14}$ Although this shows that the degree of $\mathrm{C}-\mathrm{O}$ activation depends on the charge state of the clusters, there are no indications so far for differences in the overall molecular or dissociative binding of $\mathrm{CO}$ with cationic, neutral, or anionic clusters of the same metal. Here we will focus on $\mathrm{CO}$ interaction with clusters of $\mathrm{Fe}, \mathrm{Ru}, \mathrm{Re}$, and $\mathrm{W}$ to probe the transition region for molecular versus dissociative binding of $\mathrm{CO}$ to clusters of transition metals, and to compare this to the behavior of $\mathrm{CO}$ on extended surfaces. ${ }^{3,4}$ 


\section{EXPERIMENTAL TECHNIQUES}

The IR-MPD spectra are obtained using one of two cluster beam setups. One is equipped with a pulsed gas flow ${ }^{9}$ and was used primarily for ionic clusters, while the second, which employs a cluster source with a continuous flow of helium gas, ${ }^{15}$ was used for neutral metal clusters. The range of cluster sizes and charge states reported here was determined by the ability of these two sources to produce useable cluster signal. This varies from metal to metal. For these reasons, only neutral iron and tungsten clusters and ionic ruthenium and rhenium clusters have been investigated in this study.

Metal atoms are produced in both experiments by laser ablation (frequency doubled Nd:YAG laser, $532 \mathrm{~nm}$ ) of a rotating metal rod. The atoms cluster and are carried in either a short pulse of $\mathrm{He}$ gas or a continuous flow. Carbon monoxide is subsequently introduced downstream (reaction generally at $300 \mathrm{~K}$ ). The $\mathrm{CO}$ partial pressure is adjusted to form mainly complexes with a single $\mathrm{CO}$ molecule attached. In the continuous flow experiments this corresponds to an approximate flow rate of $8 \mathrm{sccm}$ of $10 \% \mathrm{CO}$ in $\mathrm{He}$ and $2600 \mathrm{sccm} \mathrm{He}$ carrier gas. The reaction stops by expansion into vacuum and a molecular beam forms, which passes through a skimmer and a $1 \mathrm{~mm}$ aperture. In the detection chamber, the ions are accelerated by a pulsed electric field and detected by a reflectron time-of-flight mass spectrometer (Jordan TOF Products). In the study of neutral clusters, a potential is applied to the aperture to deflect ionic species, and $7.9 \mathrm{eV}$ photons emitted by an $\mathrm{F}_{2}$ laser ionize the neutral clusters in a static electric field. Care is taken to ensure the laser fluence is sufficiently low to avoid fragmentation induced by absorption of multiple UV photons.

Mass spectra are collected with and without interaction with an IR beam delivered by the Free Electron Laser for Infrared eXperiments (FELIX). ${ }^{16} \mathrm{~A}$ resonance of the IR radiation with the carbon monoxide stretching frequency of a complex can lead to the absorption of multiple IR photons and the fragmentation of $\mathrm{CO}$ from the metal clusters. FELIX is typically run with macropulse energies of $\sim 7 \mathrm{~mJ}$ at $2000 \mathrm{~cm}^{-1}$, a macropulse duration of $5 \mu \mathrm{s}$, and is scanned over the frequency range expected for the stretching vibrations of CO on metal clusters (typically $1500-2100 \mathrm{~cm}^{-1}$ ). IR depletion spectra are constructed from the IR frequency dependence of the intensity ratio of a given mass peak with and without FELIX radiation. As this detection method is mass sensitive, the IR depletion spectra for all CO-metal cluster complexes are measured simultaneously. Consequently, the quality of depletion spectra is highly dependent on cluster signal, mass distribution, FELIX performance, as well as other factors. Spectra reported here have spectral bandwidths similar to those reported previously for $\mathrm{CO}$ molecularly bound to different transition metal clusters. ${ }^{7-12} \mathrm{Ab}$ sorption of multiple photons can lead to spectral shifts in peak positions, however, as these shifts are caused by cross anharmonicities, they are expected to be small and within the linewidth of the IR laser $\left(<20 \mathrm{~cm}^{-1}\right.$ full width at half maximum). ${ }^{17}$

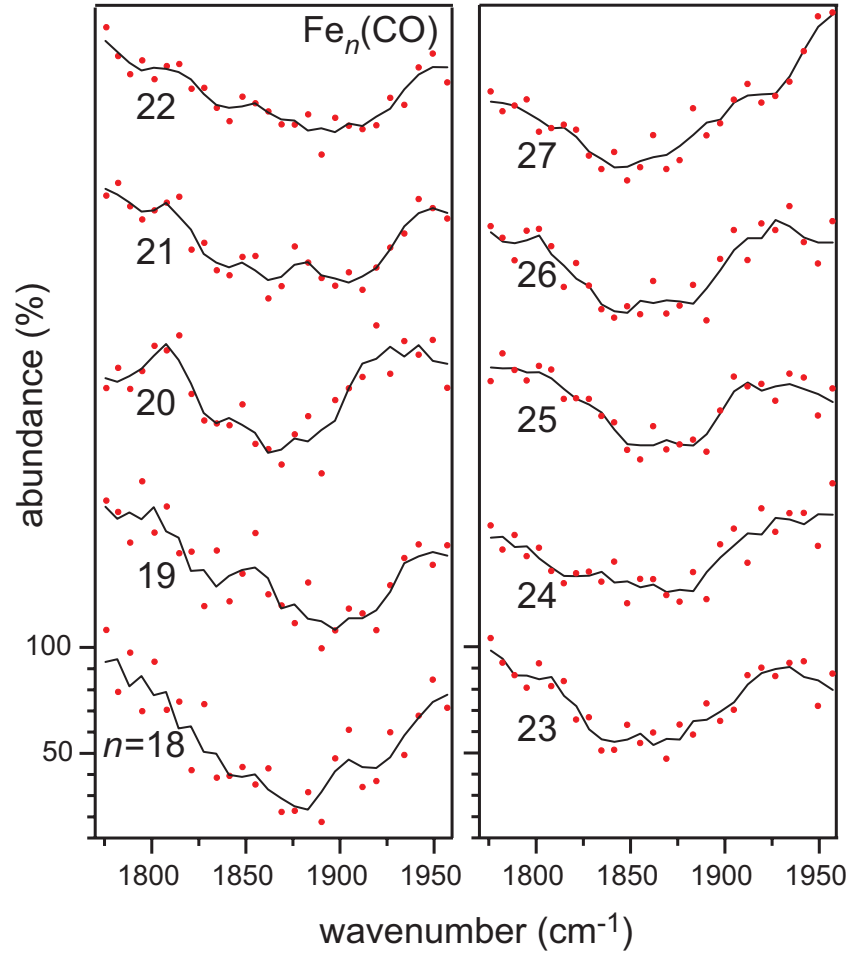

FIG. 1. IR-MPD spectra of a single carbon monoxide molecules adsorbed to neutral $\mathrm{Fe}_{n}$ clusters $(n=18-27)$. The red dots are the actual data points, while the black line interconnects its adjacent three point average.

\section{RESULTS AND DISCUSSION}

\section{A. Iron}

The IR-MPD spectra of $\mathrm{CO}$ bound on neutral $\mathrm{Fe}_{n}$ clusters $(n=18-30)$ show a single absorption band around $1865 \mathrm{~cm}^{-1}$ for all cluster sizes (Fig. 1). The intensity of the CO complexes in the mass spectra can be depleted by up to $60 \%-80 \%$ in these bands. This allows the conclusion that these bands originate from the dominant species of iron cluster CO complexes, even though only a relatively narrow frequency range $\left(1775-1950 \mathrm{~cm}^{-1}\right)$ has been scanned. The bands can be unambiguously assigned to a $\mathrm{C}-\mathrm{O}$ stretching vibration for $\mathrm{CO}$ bound to the metal cluster since oxide and carbide species formed by dissociation of $\mathrm{CO}$ on iron surfaces absorb between 400 and $550 \mathrm{~cm}^{-1}{ }^{18}$ the stretching frequencies of the diatomic $\mathrm{FeC}$ and $\mathrm{FeO}$ species are in the $800-900 \mathrm{~cm}^{-1}$ region, ${ }^{19}$ and pure iron clusters are predicted to have absorptions below $400 \mathrm{~cm}^{-1} .{ }^{20}$ Hence, it can be concluded that for the major species carbon monoxide binds molecularly to neutral iron clusters. Although we can safely make this conclusion for the major species in the molecular beam, we must also note that we do not achieve 100\% depletion in the spectra. This could be simply due to a nonperfect overlap of molecular beam and IR laser. However, it is also possible that a second structural isomer which does not absorb radiation in this spectral range (i.e., dissociatively bound $\mathrm{CO}$ on the iron clusters) may also be present in the molecular beam.

It is difficult to assign the $\mathrm{CO}$ adsorption site by direct comparison to $\mathrm{CO}$ adsorbed on iron surfaces because of diverse and partly inconsistent assignments for the vibrational bands of $\mathrm{CO}$ absorbed on iron surfaces (see below). There- 
fore, we base our assignment on established trends in $\mathrm{CO}$ binding to metal clusters. In general, one expects a stronger activation of the $\mathrm{C}-\mathrm{O}$ bond on iron as compared to later transition metals for the same binding geometry. A decrease in the $\mathrm{C}-\mathrm{O}$ bond strength and the accompanying decrease in $\nu(\mathrm{CO})$ with decreasing atomic number, within a row of transition metals is seen for $\mathrm{CO}$ bound to atop sites on clusters of the $3 d$ metals cobalt $\left(1940 \mathrm{~cm}^{-1}\right)$ and nickel $\left(1994 \mathrm{~cm}^{-1}\right)$ and also for the $4 d$ metals rhodium $\left(1960 \mathrm{~cm}^{-1}\right)$ and palladium $\left.\left(\sim 2000 \mathrm{~cm}^{-1}\right)\right)^{7,10}$ Following the trend along the $3 d$ transition metal series, we would expect the atop bound $\mathrm{CO}$ to iron clusters to show an absorption band slightly below $1900 \mathrm{~cm}^{-1}$. The observed $\mathrm{C}-\mathrm{O}$ stretching frequencies around $1865 \mathrm{~cm}^{-1}$ are in reasonable agreement with this prediction, and can on this basis be assigned to $\mathrm{CO}$ bound to atop sites on the neutral iron clusters. If $\mathrm{CO}$ were twofold bound to the iron clusters, we would expect the absorption to be redshifted an additional $150-200 \mathrm{~cm}^{-1}$.

This assignment is fully inline with earlier ones. The stretching frequency of gas phase $\mathrm{CO}$ bound to a single $\mathrm{Fe}$ atom is found at $1946 \mathrm{~cm}^{-1}$ and $\mathrm{CO}$ adsorbed at low coverage to atop sites on $\mathrm{Fe}(110)$ has a vibrational frequency of $1890 \mathrm{~cm}^{-1} \cdot{ }^{21,22}$ In our previous studies on $\mathrm{CO}$ adsorption to neutral cobalt and rhodium clusters the stretching frequency for atop bound $\mathrm{CO}$ on the clusters was systematically redshifted from values reported for $\mathrm{CO}$ bound to a single atom or adsorbed to surfaces by $30-70 \mathrm{~cm}^{-1} ;^{7}$ and we now find a similar shift for iron clusters.

However, bands at much higher frequencies have also been assigned to atop bound $\mathrm{CO}$ on other iron surfaces. For instance, for $\mathrm{CO}$ on $\mathrm{Fe}(111)$ three vibrational bands at 2000, 1805 , and $1530 \mathrm{~cm}^{-1}$ were assigned to $\mathrm{C}-\mathrm{O}$ stretching frequencies for carbon monoxide bound to atop, shallow hollow, and deep hollow sites on the surface, respectively. ${ }^{23} \mathrm{CO}$ on $\mathrm{Fe}(100)$ has been suggested to be tilted or side-on bound yielding a very low $\nu(\mathrm{CO})$ frequency around $1200 \mathrm{~cm}^{-1}$ at low coverage, whereas binding to twofold hollow sites $\left(2020 \mathrm{~cm}^{-1}\right)$ or on atop sites $\left(2070 \mathrm{~cm}^{-1}\right)$ was concluded to occur at higher coverage. ${ }^{18,24-26}$

These frequencies appear very high compared to the $1865 \mathrm{~cm}^{-1}$ we assign to atop bound $\mathrm{CO}$ adsorbed to iron clusters. They are also high compared to the values calculated for atop bound $\mathrm{CO}$ species on extended iron surfaces at low coverage, which are in the $1880-1920 \mathrm{~cm}^{-1}$ range. ${ }^{27-29}$ As the bands above $2000 \mathrm{~cm}^{-1}$ appear only at higher CO coverage on the surfaces, it might be that they are not due to isolated $\mathrm{CO}$ molecules but related to the presence of geminal carbonyls formed at low coordinated Fe atoms at steps or defects. Slab model calculations studying the mechanism of $\mathrm{Fe}(\mathrm{CO})_{5}$ formation on $\mathrm{Fe}(100)$ find that geminal binding can energetically compete with the formation of isolated $\mathrm{CO}$ ligands. ${ }^{30}$ The reduced back bonding leads to an upshift of $\nu(\mathrm{CO})$ just as in polynuclear iron carbonyls where geminal atop bound $\mathrm{CO}$ ligands have their bands typically between 2020 and $2080 \mathrm{~cm}^{-1} \cdot 31,32$

There has been a comprehensive DFT study of CO bound on small gas-phase iron clusters. ${ }^{33}$ It predicts that two-, three-, and fourfold coordinated $\mathrm{CO}$ species form the most stable binding geometry in $\mathrm{Fe}_{3,4}, \mathrm{Fe}_{5}$, and $\mathrm{Fe}_{6}$, respec-
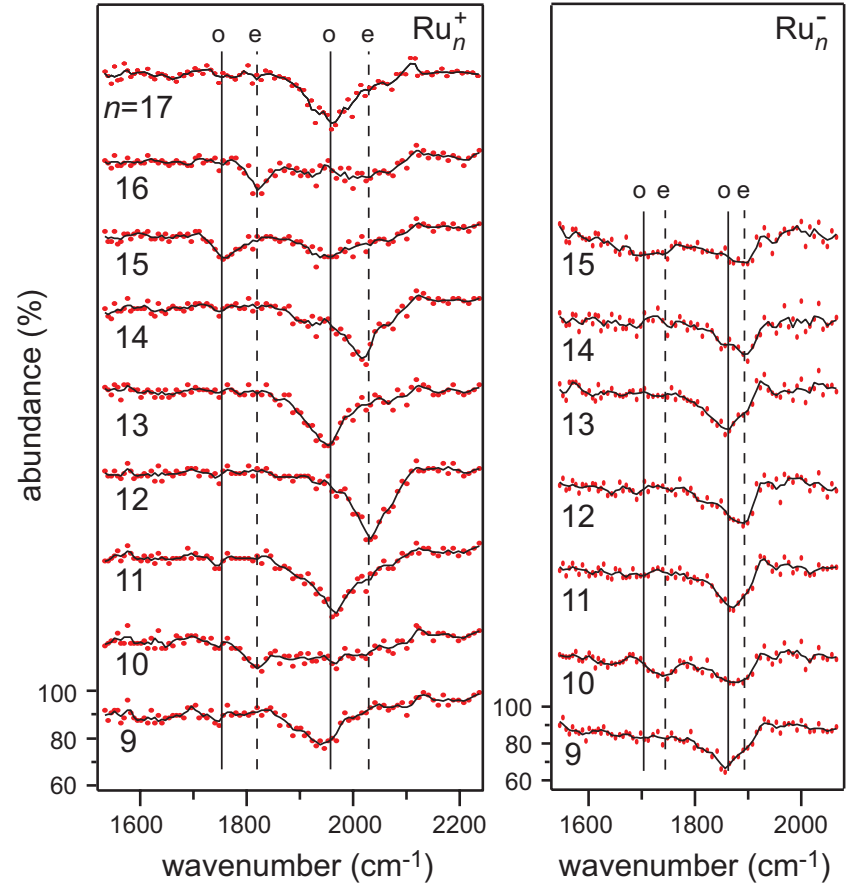

FIG. 2. IR-MPD spectra of a single carbon monoxide adsorbed to ionic $\mathrm{Ru}_{n}{ }^{+/-}$clusters $(n=9-17)$. The red dots are the actual data points, while the black line interconnects its adjacent three point average. The solid and dashed lines indicate the absorptions on odd and even numbered clusters, respectively.

tively. The reported $\mathrm{CO}$ stretching frequencies for these species are significantly below our experimental values for $\mathrm{CO}$ atop bound to $\mathrm{Fe}_{18-30}$, as would be expected. Unfortunately, we were unable to measure clusters this small to confirm the transition from high coordination binding in small clusters to atop binding in large clusters, which has some parallels in rhodium cluster $\mathrm{CO}$ complexes. ${ }^{8}$

\section{B. Ruthenium}

In the case of ruthenium clusters, we studied the interaction of $\mathrm{CO}$ with the cationic and anionic species containing 4-19 Ru atoms. Infrared spectra of carbon monoxide adsorbed on ionic ruthenium clusters are shown in Fig. 2. The highest frequency bands are observed at $\sim 2000 \mathrm{~cm}^{-1}$ on cationic ruthenium clusters, and around $1870 \mathrm{~cm}^{-1}$ for anionic clusters.

Assignments of the observed bands can be made by comparison with $\nu(\mathrm{CO})$ values for $\mathrm{CO}$ bound to extended ruthenium surfaces. For rhodium clusters (one element to the right of Ru in the Periodic Table), we found that $\nu(\mathrm{CO})$ for carbon monoxide adsorbed to larger $(n \geq 10)$ cationic clusters tends to be close to surface values. ${ }^{7}$ As the stretching frequencies for atop bound $\mathrm{CO}$ on ruthenium surfaces are reported to be in the $1980-2010 \mathrm{~cm}^{-1}$ region, ${ }^{34-39}$ the higher frequency bands for $\mathrm{CO}$ adsorbed on cationic ruthenium clusters are assigned to atop bound $\mathrm{CO}$. Also, the cationic $\mathrm{RuCO}^{+}$complex has a $\mathrm{C}-\mathrm{O}$ stretching frequency of $2135 \mathrm{~cm}^{-1}$ in a neon matrix, ${ }^{40,41}$ and for larger cationic clusters this frequency should shift to the red as more ruthenium atoms become available to delocalize the positive charge. ${ }^{7}$ For anionic clusters containing about $10 \mathrm{Ru}$ atoms $\nu(\mathrm{CO})$ 
assigned to atop bound $\mathrm{CO}$ is redshifted from the cationic counterpart by roughly $100-150 \mathrm{~cm}^{-1}$, which is very similar to the shift observed for rhodium clusters. ${ }^{7}$

In Fig. 2, a second set of absorption bands is apparent around $1800 \mathrm{~cm}^{-1}$ for the cationic clusters $\mathrm{Ru}_{10} \mathrm{CO}^{+}$, $\mathrm{Ru}_{15} \mathrm{CO}^{+}$, and $\mathrm{Ru}_{16} \mathrm{CO}^{+}$, and at 1740 and $1711 \mathrm{~cm}^{-1}$ for $\mathrm{Ru}_{10} \mathrm{CO}^{-}$and $\mathrm{Ru}_{15} \mathrm{CO}^{-}$, respectively. As the predictions for $\nu(\mathrm{CO})$ for atop and bridge sites on $\mathrm{Ru}(0001)$ are separated by approximately $170 \mathrm{~cm}^{-1}$, ${ }^{42}$ the redshift of about $200 \mathrm{~cm}^{-1}$ from the bands assigned to atop $\mathrm{CO}$ on ruthenium clusters leads us to assign the second set to $\mathrm{CO}$ bound to bridge sites. It is interesting to note that the bridge bounded carbonyls are observed for the same sized anions and cations. This might point to common geometric arrangements of these clusters and a structural reason for the appearance of bridge bound $\mathrm{CO}$ ligands.

It is remarkable that the $\mathrm{C}-\mathrm{O}$ stretching frequency for carbon monoxide adsorbed to odd numbered ruthenium clusters usually is observed at lower frequencies than for clusters with an even number of ruthenium atoms (see Fig. 2). This is particularly striking for $\nu(\mathrm{CO})$ assigned to atop bound $\mathrm{CO}$ to cationic clusters containing 7-17 $\mathrm{Ru}$ atoms, where the separation is $30-100 \mathrm{~cm}^{-1}$; for the anionic clusters the difference is only approximately $15 \mathrm{~cm}^{-1}$. A similar shift is observed for $\nu(\mathrm{CO})$ assigned to bridge bound $\mathrm{CO}$; complexes exhibiting a low value for atop- $\nu(\mathrm{CO})$ also show a low frequency for bridge- $\nu(\mathrm{CO})$. Such a pronounced size dependence in $\nu(\mathrm{CO})$, which is very different to the gradual shift related to the charge dilution in ionic clusters, has not been detected for other metals before. We considered multiple possible explanations for the observed shifts in the frequency based on predicted trends in the electronic and structural properties. However, most of these predictions are based on the assumption of cubic cluster structures, ${ }^{43,44}$ which may not be the real ground-state structures but merely an artifact of neglecting exact exchange in the density functional theory calculations. ${ }^{45,46}$ Clearly, a better understanding of the bare ruthenium clusters is required before an explanation of the observed trends in $\nu(\mathrm{CO})$ can be given.

\section{Rhenium}

According to Brodèn, rhenium should be the lightest $5 d$ metal to which CO binds molecularly. ${ }^{3,4}$ Indeed, the IR depletion spectra for cationic rhenium clusters containing up to $13 \mathrm{Re}$ atoms complexed with carbon monoxide (Fig. 3) reveal the presence of molecularly bound $\mathrm{CO}$. Here, we show the spectra of complexes with two $\mathrm{CO}$ molecules as well, as some bands are hardly visible in the complex with a single CO molecule but become more apparent in the complex with two $\mathrm{CO}$ molecules. The overall behavior, including the observed $\nu(\mathrm{CO})$ values, is very similar in the complexes with one and two $\mathrm{CO}$ ligands.

Absorption bands are observed at three distinctly different regions in the spectra depending on cluster size (Fig. 3). Bands appear in the 1990-2070 $\mathrm{cm}^{-1}$ region (the absorption peaks for $\mathrm{Re}_{7}$ and $\mathrm{Re}_{11-13}$ are more pronounced when two $\mathrm{CO}$ ligands are bound to the clusters), which show a noticeable redshift with increasing cluster size. Again, these $\nu(\mathrm{CO})$
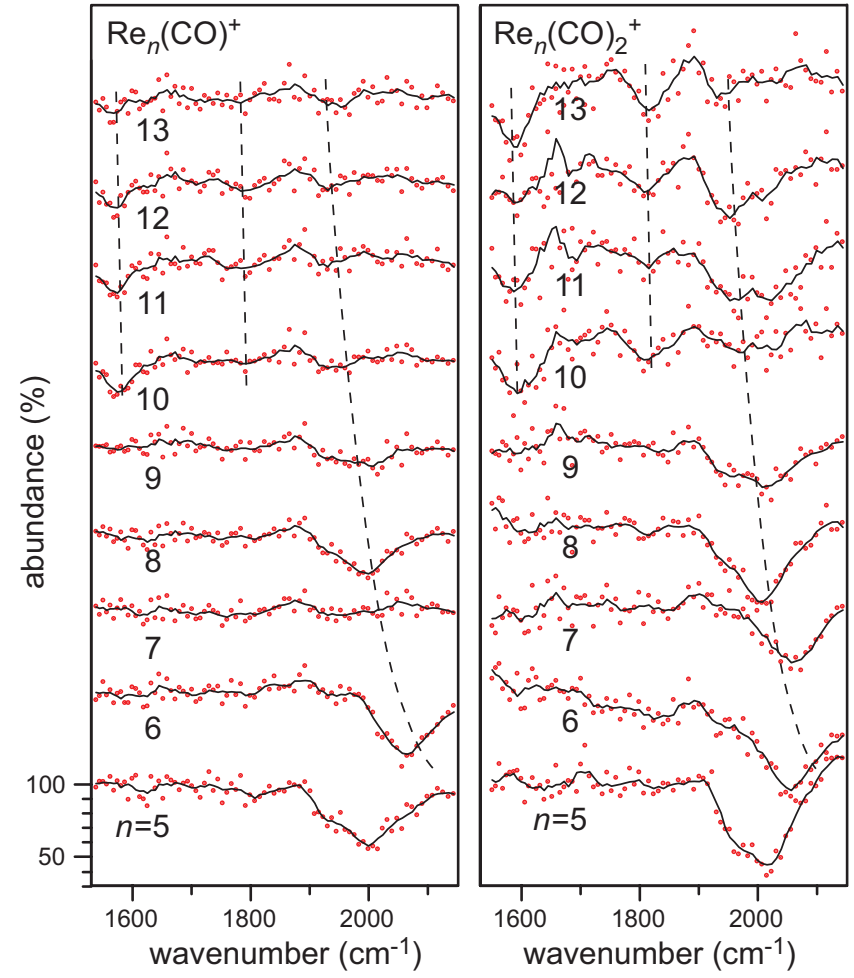

FIG. 3. IR-MPD spectra of one and two carbon monoxide molecules adsorbed to cationic $\operatorname{Re}_{n}{ }^{+}$clusters $(n=5-14)$. The red dots are the actual data points, while the black line interconnects its adjacent three point average. The dashed vertical lines indicate the approximate position of the CO absorptions for this cluster size range.

values are similar to the $\mathrm{CO}$ stretching frequency for carbon monoxide adsorbed on an atop position to $\operatorname{Re}(0001)$ surfaces, which appears at $1990 \mathrm{~cm}^{-1}$ at low coverage ${ }^{47}$ Hence, these high frequency absorptions are again most likely due to $\mathrm{CO}$ atop bound to the cationic rhenium clusters. For larger clusters $(n=10-13)$, bands also occur around $1800 \mathrm{~cm}^{-1}$; stronger depletions are observed when two $\mathrm{CO}$ molecules are bound. The separation of roughly $200 \mathrm{~cm}^{-1}$ from the signals assigned to atop bound $\mathrm{CO}$ is similar to that for the ruthenium clusters and indicates the bands arise from $\mathrm{CO}$ bridge bound to the cationic rhenium clusters. Additional signals are observed at even lower frequencies, around $1575 \mathrm{~cm}^{-1}$. Considering the shift of again about $200 \mathrm{~cm}^{-1}$ from the $\nu(\mathrm{CO})$ of bridged bound species, these bands are probably due to $\mu_{3}$-CO bound to a hollow site on the cationic rhenium clusters. Similar hollow site binding has been previously observed for ionic palladium clusters. ${ }^{10}$

\section{Tungsten}

The IR depletion spectra for neutral $\mathrm{W}_{n} \mathrm{CO}(n=5-14)$ are shown in Fig. 4. For $\mathrm{W}_{n} \mathrm{CO}(n=5,7-9,11)$, broad bands appear in the spectrum in the $1700-1950 \mathrm{~cm}^{-1}$ range. For $n=5,9$, and 11 these bands have a more pronounced minimum at $\sim 1925 \mathrm{~cm}^{-1}$. To validate the character of these bands, additional experiments were performed with ${ }^{13} \mathrm{CO}$ (red line in Fig. 4). Although it is not clear whether the broad absorption for $\mathrm{W}_{7} \mathrm{CO}$ shifts with carbon-13 substitution, a redshift in the absorption bands according to the increase in the reduced mass is clearly present for the other cluster sizes. 


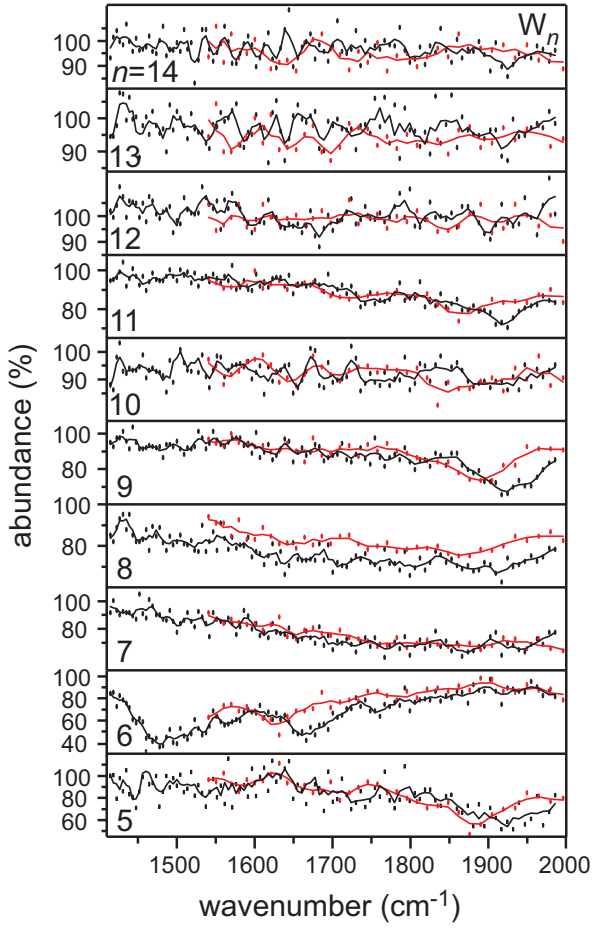

FIG. 4. IR-MPD spectra of ${ }^{12} \mathrm{CO}$ (black) and ${ }^{13} \mathrm{CO}$ (red) molecules adsorbed to neutral $\mathrm{W}_{n}$ clusters $(n=5-14)$. The dots are the actual data points, while the lines interconnect its adjacent three point average.

We tentatively assign these bands at $1925 \mathrm{~cm}^{-1}$ to $\mathrm{CO}$ atop bound to the clusters. Unfortunately, no direct comparison with $\mathrm{CO}$ on tungsten surfaces can be made, as here $\mathrm{CO}$ dissociates and only $\nu(\mathrm{CO})$ values for carbon precovered surfaces have been determined $\left(2040-2100 \mathrm{~cm}^{-1}\right){ }^{48,49}$

In all of our investigations on $\mathrm{CO}$ adsorption to metal clusters, this is the first time that we have seen that the chemistry occurring on extended surfaces is clearly different from the chemistry occurring on small gas-phase clusters. For $\mathrm{W}_{6} \mathrm{CO}$, two absorption bands are present at 1665 and $1500 \mathrm{~cm}^{-1}$. The one at $1665 \mathrm{~cm}^{-1}$ is approximately $260 \mathrm{~cm}^{-1}$ below the $\nu(\mathrm{CO})$ assigned to atop bound $\mathrm{CO}$, whereas the $1500 \mathrm{~cm}^{-1}$ band is an additional $165 \mathrm{~cm}^{-1}$ redshifted. Although these separations are slightly different from the $\sim 200 \mathrm{~cm}^{-1}$ shifts observed for the more coordinated $\mathrm{CO}$ on the ionic ruthenium and rhenium clusters, they most likely are due to bridge bound and hollow site bound $\mathrm{CO}$, respectively. For $\mathrm{W}_{10} \mathrm{CO}$ and $\mathrm{W}_{n} \mathrm{CO}(n \geq 12)$, no noticeable absorption bands are observed (note the different intensity scale for these sizes in Fig. 4). Although not a definitive proof, this indicates the general absence of molecular $\mathrm{CO}$ ligands due to the dissociation of carbon monoxide on these sized clusters. Hence, tungsten apparently shows size dependant nondissociative bonding of carbon monoxide on the clusters. Only for larger sized tungsten clusters does CO appear to dissociate. With respect to the $\mathrm{CO}$ binding behavior, bulklike properties already emerge for tungsten metal clusters containing more than 11 atoms. For extended tungsten surfaces, $\mathrm{CO}$ that is adsorbed initially at low temperature in a "virgin" molecular state is found to dissociate near room temperature $^{50}$ Additional molecular $(\alpha-\mathrm{CO})$ states are known to exist, but get only populated subsequent to satura-

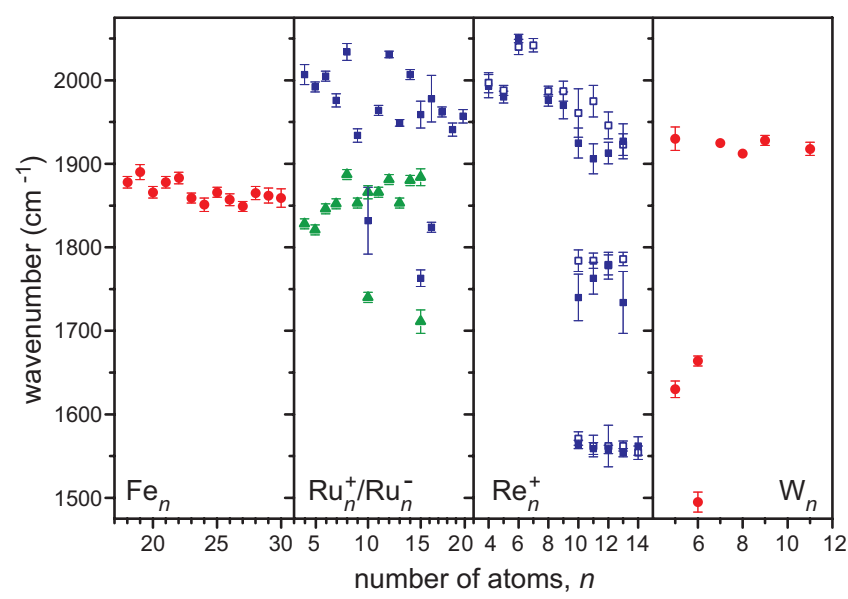

FIG. 5. A plot of the observed CO stretching frequency on metal clusters $\left(\mathrm{M}_{n}\right)$ vs cluster size $n$. From left to right, the first panel indicates the observed frequency on neutral iron clusters (red circles). The second panel indicates the observed frequency on cationic (blue squares) and anionic (green triangles) ruthenium clusters. The third panel indicates the observed frequency of one (solid blue squares) and two (open blue squares) $\mathrm{CO}$ molecules adsorbed on cationic rhenium clusters. The fourth panel indicates the observed frequency on neutral tungsten clusters (red circles).The peak positions are determined from a least-squares fit to a Gaussian line shape. The error bars indicate twice the standard deviation $(1 \sigma)$ of the fits.

tion of the dissociative $\beta$-CO state. ${ }^{48,51}$ In our experiments, cooling the reaction channel from $\sim 300$ to $100 \mathrm{~K}$ did not change the $\mathrm{CO}$ binding behavior on the clusters. Finally, it should be noted that carbon monoxide is found to completely dissociate on neutral clusters containing 4-20 atoms of tantalum, the element to the left of tungsten in the Periodic Table.

\section{E. Periodic trends}

Figure 5 shows a plot of the assigned frequencies for $\mathrm{CO}$ adsorbed to these metal clusters as a function of cluster size. The values of $\nu(\mathrm{CO})$ assigned to atop bound $\mathrm{CO}$ on the charged clusters gradually shift with increasing cluster size to lower frequencies for the cations and to higher frequencies for the anions. This is similar as observed before for other metals and can be related to the charge dilution effect. ${ }^{7}$ Here, however, this is superimposed by strong size-dependent fluctuations. To illustrate the trends in the $\mathrm{C}-\mathrm{O}$ bond activation across the transition metals, the observed (averaged) $\nu(\mathrm{CO})$ values assigned to atop bound $\mathrm{CO}$ on neutral metal clusters are plotted versus the group number in Fig. 6. The plot uses data reported here, but also from our previous experiments. ${ }^{7-12,14}$ For iron and tungsten the average of $\nu(\mathrm{CO})$ of all neutral clusters is used, whereas for ruthenium the average of $\nu(\mathrm{CO})$ for the cationic and anionic species is taken as the average value for the neutral cluster.

The trends for $\nu(\mathrm{CO})$ can be explained by the evolution of the electronic properties within the transition metals. For metal carbonyls, $\sigma$ bonding between the metal center and $\mathrm{CO}$ ligands is found to have no major influence of the $\mathrm{C}-\mathrm{O}$ stretching frequency, but rather it is the $\pi$ back-bonding interaction which has a strong influence on $\nu(\mathrm{CO}) .^{7,52}$ Moving to the left in the Periodic Table results in a rise of the metal Fermi energy level and of the diffuseness of the metal's $d$ 


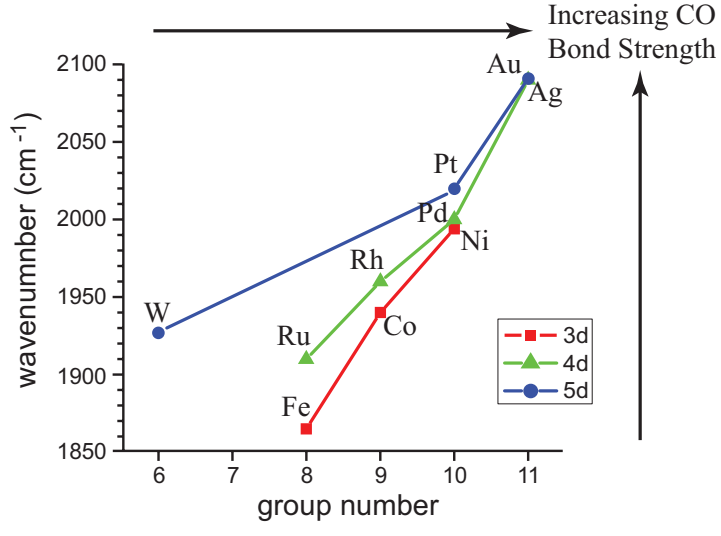

FIG. 6. A plot of the observed $\mathrm{C}-\mathrm{O}$ stretching frequency vs group number for $\mathrm{CO}$ bound in atop positions on neutral clusters. The values for the $4 d$ metals $\mathrm{Ru}$ and $\mathrm{Pd}$ (group 8 and 10) are taken as the average value for the anionic and cationic clusters.

electrons. This results in more $\pi$ back-bonding to the $\mathrm{CO}$ antibonding $2 \pi$ orbital, and the weakening of the $\mathrm{C}-\mathrm{O}$ bond, until $\mathrm{CO}$ binds dissociatively. ${ }^{53}$ Consequently, the $\mathrm{C}-\mathrm{O}$ stretching frequency for $\mathrm{CO}$ adsorbed on clusters of early transition metals are at lower frequencies than those of the later transition metal clusters. Similarly, the Fermi energy level becomes increasingly lower moving down a family, and the $\mathrm{C}-\mathrm{O}$ stretching frequency increases successively when going from the $3 d$ metal to the heavier homologs.

\section{CONCLUSION}

IR-MPD spectra of carbon monoxide adsorbed to clusters of iron, ruthenium, rhenium, and tungsten have been presented. It is found that $\mathrm{CO}$ binds molecularly in atop position on neutral iron clusters. For ionic ruthenium clusters, $\mathrm{CO}$ binds molecularly not only in atop positions, but also more coordinated bridge bound species are observed for selected cluster sizes. An even-odd oscillatory behavior in the frequency of the $\mathrm{C}-\mathrm{O}$ stretching mode is observed with the number of Ru atoms in the cluster. On small neutral tungsten clusters and cationic rhenium clusters carbon monoxide binds molecularly to atop, bridge, and hollow sites. For larger tungsten clusters, $\mathrm{CO}$ binds dissociatively. These findings demonstrate that Brodèn's proposal indicating which metal surfaces would molecularly or dissociatively adsorb $\mathrm{CO}$ also holds true, for the most part, for small clusters of transition metals. The observed change in $\nu(\mathrm{CO})$ allows a more quantitative description of the weakening of the $\mathrm{C}-\mathrm{O}$ bonds and is largely in agreement with the trends on extended surfaces.

\section{ACKNOWLEDGMENTS}

We thank the FELIX staff for their assistance, in particular Dr. Britta Redlich and Dr. A. F. G. van der Meer. This work is supported by the Stichting voor Fundamenteel Onderzoek der Materie (FOM) in providing beam time for FELIX, and by the European Community-Research Infrastructure Action under the FP6 "Structuring the European Research Area" Program (through the Integrated Infrastructure Initiative "Integrating Activity on Synchrotron and Free
Electron Laser Science"). J.T.L. thanks the Alexander von Humboldt Foundation. We acknowledge support by the Cluster of Excellence "Unifying concepts in Catalysis" coordinated by the Technische Universität Berlin and funded by the Deutsche Forschungsgemeinschaft (DFG) as well as funding by the DFG (Grant No. FI 893/3-1).

${ }^{1}$ M. E. Dry, Catal. Today 71, 227 (2002).

${ }^{2}$ T. Bligaard, J. K. Nørskov, S. Dahl, J. Matthiesen, C. H. Christensen, and J. Sehested, J. Catal. 224, 206 (2004).

${ }^{3}$ G. Brodèn, T. N. Rhodin, C. Brucker, R. Benbow, and Z. Hurych, Surf. Sci. 59, 593 (1976).

${ }^{4}$ W. Andreoni and C. M. Varma, Phys. Rev. B 23, 437 (1981).

${ }^{5}$ I. Swart, A. Fielicke, B. Redlich, G. Meijer, B. M. Weckhuysen, and F. M. F. de Groot, J. Am. Chem. Soc. 129, 2516 (2007)

${ }^{6}$ D. B. Pedersen, D. M. Rayner, B. Simard, M. A. Addicoat, M. A. Buntine, G. F. Metha, and A. Fielicke, J. Phys. Chem. A 108, 964 (2004).

${ }^{7}$ A. Fielicke, G. von Helden, G. Meijer, D. B. Pedersen, B. Simard, and D. M. Rayner, J. Chem. Phys. 124, 194305 (2006).

${ }^{8}$ A. Fielicke, G. von Helden, G. Meijer, D. B. Pedersen, B. Simard, and D. M. Rayner, J. Phys. Chem. B 108, 14591 (2004).

${ }^{9}$ A. Fielicke, G. von Helden, G. Meijer, B. Simard, S. Dénommée, and D. M. Rayner, J. Am. Chem. Soc. 125, 11184 (2003).

${ }^{10}$ P. Gruene, A. Fielicke, G. Meijer, and D. M. Rayner, Phys. Chem. Chem. Phys. 10, 6144 (2008).

${ }^{11}$ A. Fielicke, G. von Helden, G. Meijer, B. Simard, and D. M. Rayner, J. Phys. Chem. B 109, 23935 (2005).

${ }^{12}$ A. Fielicke, G. von Helden, G. Meijer, D. B. Pedersen, B. Simard, and D. M. Rayner, J. Am. Chem. Soc. 127, 8416 (2005).

${ }^{13}$ G. Blyholder, J. Phys. Chem. 68, 2772 (1964).

${ }^{14}$ A. Fielicke, P. Gruene, G. Meijer, and D. M. Rayner, Surf. Sci. 603, 1427 (2009).

${ }^{15}$ J. Opitz-Coutureau, A. Fielicke, B. Kaiser, and K. Rademann, Phys. Chem. Chem. Phys. 3, 3034 (2001).

${ }^{16}$ D. Oepts, A. F. G. van der Meer, and P. W. van Amersfoort, Infrared Phys. Technol. 36, 297 (1995).

${ }^{17}$ J. Oomens, A. J. A. van Roij, G. Meijer, and G. von Helden, Astrophys. J. 542, 404 (2000).

${ }^{18}$ J.-P. Lu, M. R. Albert, and S. L. Bernasek, Surf. Sci. 217, 55 (1989).

${ }^{19}$ G. L. Gutsev, L. Andrews, and C. W. Bauschlicher, Jr., Theor. Chem. Acc. 109, 298 (2003).

${ }^{20}$ S. Yu, S. Chen, W. Zhang, L. Yu, and Y. Yin, Chem. Phys. Lett. 446, 217 (2007).

${ }^{21}$ K. Tanaka, S. Sakaguchi, and T. Tanaka, J. Chem. Phys. 106, 2118 (1997).

${ }^{22}$ W. Erley, J. Vac. Sci. Technol. 18, 472 (1981).

${ }^{23}$ U. Seip, M.-C. Tsai, K. Christmann, J. Küppers, and G. Ertl, Surf. Sci. 139, 29 (1984)

${ }^{24}$ S. L. Bernasek, Annu. Rev. Phys. Chem. 44, 265 (1993).

${ }^{25}$ D. W. Moon, S. L. Bernasek, D. J. Dwyer, and J. L. Gland, J. Am. Chem. Soc. 107, 4363 (1985).

${ }^{26}$ D. W. Moon, S. L. Bernasek, J.-P. Lu, J. L. Gland, and D. J. Dwyer, Surf. Sci. 184, 90 (1987).

${ }^{27}$ D. C. Sorescu, D. L. Thompson, M. M. Hurley, and C. F. Chabalowski, Phys. Rev. B 66, 035416 (2002).

${ }^{28}$ T. C. Bromfield, D. C. Ferré, and J. W. Niemantsverdriet, ChemPhysChem 6, 254 (2005).

${ }^{29}$ D. C. Sorescu, J. Phys. Chem. C 112, 10472 (2008).

${ }^{30}$ H. Cheng, D. B. Reiser, S. W. Dean, and K. Baumert, J. Phys. Chem. B 105, 12547 (2001).

${ }^{31}$ R. K. Sheline, J. Am. Chem. Soc. 73, 1615 (1951).

${ }^{32}$ J. W. Cable and R. K. Sheline, Chem. Rev. (Washington, D.C.) 56, 1 (1956).

${ }^{33}$ G. L. Gutsev, C. W. Bauschlicher, Jr., and L. Andrews, J. Chem. Phys. 119, 3681 (2003).

${ }^{34}$ P. Jakob, Phys. Rev. Lett. 77, 4229 (1996).

${ }^{35}$ M. Bonn, C. Hess, W. G. Roeterdink, H. Ueba, and M. Wolf, Chem. Phys. Lett. 388, 269 (2004).

${ }^{36}$ Y. K. Kim, G. A. Morgan, Jr., and J. T. Yates, Jr., J. Phys. Chem. C 111, 3366 (2007).

${ }^{37}$ S. Ishi, Y. Ohno, and B. Viswanathan, Surf. Sci. 161, 349 (1985).

${ }^{38}$ D. Heskett, E. W. Plummer, and R. P. Messmer, Surf. Sci. 139, 558 (1984). 
${ }^{39}$ H. Pfnür, D. Menzel, F. M. Hoffmann, A. Ortega, and A. M. Bradshaw, Surf. Sci. 93, 431 (1980).

${ }^{40}$ M. Zhou, L. Andrews, and C. W. Bauschlicher, Jr., Chem. Rev. (Washington, D.C.) 101, 1931 (2001).

${ }^{41}$ M. Zhou and L. Andrews, J. Phys. Chem. A 103, 6956 (1999).

${ }^{42}$ F. Abild-Pedersen and M. P. Andersson, Surf. Sci. 601, 1747 (2007).

${ }^{43}$ W. Zhang, H. Zhao, and L. Wang, J. Phys. Chem. B 108, 2140 (2004).

${ }^{44} \mathrm{~S}$. Li, H. Li, J. Liu, X. Xue, Y. Tian, H. He, and Y. Jia, Phys. Rev. B 76, 045410 (2007).

${ }^{45}$ L. L. Wang and D. D. Johnson, J. Phys. Chem. B 109, 23113 (2005).
${ }^{46}$ D. J. Harding, T. R. Walsh, S. M. Hamilton, W. S. Hopkins, S. R. Mackenzie, P. Gruene, M. Haertelt, G. Meijer, and A. Fielicke, submitted.

${ }^{47}$ R. Ducros, B. Tardy, and J. C. Bertolini, Surf. Sci. 128, L219 (1983).

${ }^{48}$ C. M. Friend, J. G. Serafin, E. K. Baldwin, P. A. Stevens, and R. J. Madix, J. Chem. Phys. 87, 1847 (1987).

${ }^{49}$ R. Franchy and H. Ibach, Surf. Sci. 155, 15 (1985).

${ }^{50}$ E. Umbach and D. Menzel, Surf. Sci. 135, 199 (1983).

${ }^{51}$ D. M. Riffe and A. J. Sievers, Surf. Sci. 297, 1 (1993).

${ }^{52}$ A. S. Goldman and K. Krogh-Jespersen, J. Am. Chem. Soc. 118, 12159 (1996).

${ }^{53}$ S. S. Sung and R. Hoffmann, J. Am. Chem. Soc. 107, 578 (1985). 